\begin{abstract}
REPLY
Nuisance conditions experienced by Dr. Webster, such as "frozen" keyboards and unresponsive patient control buttons, have been associated with exposure of the pump to an electrostatic discharge (ESD). During extensive testing we found that the Bard PCA* Pump is primarily susceptible to ESD through pump attachments, namely the patient control and printer interface. We also confirmed that ESD problems are most likely to occur in cold, dry climates. After identifying the cause of ESD effects on the pump, we have developed appropriate product enhancements. New cables have been designed to shield from ESD the patient control and printer interface cables to the pump. Shielded cables, as well as grounding improvements to the printer interface circuit board, will serve to further minimize the device experiencing a safe shut-down resulting from ESD exposure. These enhancements will be incorporated into the product during the month of November. At the time of this writing. Bard Canada has implemented a no charge cable replacement program for all present Bard PCA* System users.
\end{abstract}

P. Randall Eidt

Product Manager

Bard Canada Inc.

"Trademark

\section{Epidural buprenorphine}

To the Editor:

Ackerman et al., ${ }^{1}$ from the University of Cincinnati, Ohio, report a well-conducted study of pruritus associated with epidural opiates. The drugs studied were $5 \mathrm{mg}$ morphine, $50 \mu \mathrm{g}$ fentanyl, $0.3 \mathrm{mg}$ buprenorphine, or 1 $\mathrm{mg}$ butorphanol in $10 \mathrm{ml}$. Two concerns emerge about the use of buprenorphine by this route of administration: (i) the absence of approval by the appropriate regulatory authorities, and (ii) whether this route of administration leads to any pharmacokinetic or pharmacodynamic advantage.

As a pharmaceutical physician at Norwich Eaton, the company responsible for Buprenex in the USA, I am obliged to point out that this is not an approved route of administration for buprenorphine in this country. While the parenteral formulation may be attractive for epidural studies because it contains no organic preservatives, the anaesthetist should be informed that he or she uses this route of administration with the risks which attend unapproved usage.

Buprenorphine is a highly lipophilic, potent and parenterally long-acting analgesic, ${ }^{2,3}$ and is an exception to the general rule that epidural doses of opioids are smaller than parenteral doses. Compare, for example, equianalgesic doses of buprenorphine and morphine by the two routes of administration. A standard parenteral dose of buprenorphine is $0.3 \mathrm{mg}$. Lanz et al. ${ }^{2}$ directly compared epidural doses of $0.3 \mathrm{mg}$ and $0.15 \mathrm{mg}$ buprenorphine, and showed that the former gave better analgesia; these data suggest that the parenteral/epidural $(\mathrm{P} / \mathrm{E})$ analgesic dose ratio for buprenorphine equals 1 . This $\mathrm{P} / \mathrm{E}$ ratio is confirmed by other, less rigorous, single epidural dose studies. ${ }^{1,4-8}$

The low $\mathrm{P} / \mathrm{E}$ dose ratio, and the similarity of duration of action by the epidural and parenteral routes, suggest that there is no advantage to be gained by the administration of buprenorphine using the epidural route. Furthermore, these data are consistent with an analgesic effect which may be entirely due to systemic absorption. The profile of adverse effects dependent upon this route of administration is relatively unknown. ${ }^{6}$ In the absence of any pharmacokinetic or pharmacodynamic advantage, the epidural route of administration must be considered to be redundant for buprenorphine.
A.W. Fox, BSc MBBS MD
Norwich Eaton Pharmaceuticals, Norwich, NY, 13815, U.S.A.

\section{REFERENCES}

1 Ackerman WE, Juneja MM, Kaczorowski DM, Colclough $G W$. A comparison of the incidence of pruritus following epidural opioid administration in the parturient. Can J. Anaesth 1989; 36: 388-91.

2 Downing JW, Leary WP, White ES. Buprenorphine: a new potent long-acting synthetic analgesic. Comparison with morphine. Br J Anaesth 1977; 49: 251-5.

3 Dobkin $A B$. Buprenorphine hydrochloride: determination of analgesic potency. Can Anaesth Soc J 1977; 24: 18694

4 Chrubasik J, Vogel W, Trötschler H, Farthmann $E H$. "Continuous-plus-on-demand" epidural infusion of buprenorphine versus morphine in post-operative treatment of pain. Arzneimittel forschung 1987; 37: 361-3.

5 Jensen FM, Jensen NH, Holk IK, Ravnborg M. Prolonged and biphasic respiratory depression following epidural buprenorphine. Anaesthesia 1987; 42: 470-5.

6 MacEvilly $M, O^{\prime}$ Carroll. Hallucinations after epidural buprenorphine. Br Med J 1989; 298: 928-9.

7 Wolff J, Carl P, Crawford ME. Epidural buprenorphine for post-operative analgesia. A controlled comparison with epidural morphine. Anaesthesia 1986; 46: 77-9.

8 Bilsback $P$, Rolly $G$, Tampubolon $O$. Efficacy of the extradural administration of lofentanil, buprenorphine or saline in the management of post-operative pain. $\mathrm{Br} \mathrm{J}$ Anaesth 1985; 57: 943-8.

\section{REPLY}

We would like to thank Dr. Fox for his interest in our article ${ }^{l}$ and his discussion of the comparison of buprenorphine with morphine. We were aware that the lipophilic opioids used in our study were not FDA approved for epidural use. For this reason 